\title{
Molecular structure, chemical reactivity, stability and vibrational spectroscopic investigation of stearic and palmitic acid using density functional theory
}

\author{
Ituen, E. B. ${ }^{a(\#)}$, Akpan, I. J. ${ }^{a}$, Oluwaseyi, O. R. ${ }^{b}$ \\ ${ }^{a}$ Physical Chemistry Research Unit, Department of Chemistry, University of Uyo, Nigeria \\ ${ }^{b}$ Department of Science Technology, Federal Polytechnic, Ado-Ekitti, Nigeria
}

\begin{abstract}
The molecular structures of stearic acid and palmitic acid were simulated using density functional theory $(D F T)$ at the B3LYP/6-31G*basis set level with a view to compare their reactivity and stability based on some theoretically calculated parameters. The energy gap between the HOMO and LUMO of both fatty acids were found to be similar (7.76 eV) and independent of alkyl residue. The total energy (absolute values) of stearic acid was found to be higher than that of palmitic acid. Values of global hardness and softness indicate significant chemical reactivity and stability of both molecules. Spectroscopic investigation gives similar spectral positions while slight differences in dipole moment values suggests higher reactivity of palmitic acid than stearic acid.
\end{abstract}

Keywords: Chemical reactivity, DFT, palmitic acid, stability, stearic acid.

\section{Introduction}

Stearic acid is a saturated fatty acid with an 18-carbon chain and has the IUPAC name octadecanoic acid. It is a waxy solid having the chemical formula $\mathrm{CH}_{3}\left(\mathrm{CH}_{2}\right)_{16} \mathrm{CO}_{2} \mathrm{H}$. Salts or esters of stearic acid are called stearates [1]. Palmitic acid, or hexadecanoic acid in IUPAC nomenclature, is the most common fatty acid (saturated) found in animals, plants and microorganisms [1]. Its molecular formula is $\mathrm{CH}_{3}\left(\mathrm{CH}_{2}\right)_{14} \mathrm{CO}_{2} \mathrm{H}$. As its name indicates, it is a major component of the oil from palm trees (palm oil, palm kernel, and palm kernel oil), but can also be found in meats, cheeses, butter, and dairy products. Palmitate is a term for the salts and esters of palmitic acid. The palmitate anion is the observed form of palmitic acid at basic $\mathrm{pH}$. Both fatty acids are commonly used in manufacture of soaps, cosmetics and release agents. Table 1 below shows a summary of physical properties of stearic and palmitic acids for easy comparison.

Table 1: Some physical properties of stearic acid and palmitic acid.

\begin{tabular}{lll}
\hline Properties & Stearic acid & Palmitic acid \\
\hline Molecular mass (g/mol) & 284.48 & 256.42 \\
Appearance & White solid & White crystal \\
Density (g/L) & 0.847 at $343 \mathrm{~K}$ & $0, .835$ at $335 \mathrm{~K}$ \\
Melting point $(\mathbf{K})$ & 343 & 335 \\
Boiling point(K) & 652 & $624-625$ \\
Solubility in water (g/L at 313 K) & 3.0 & Insoluble \\
\hline
\end{tabular}

\section{Computational Method}

Density functional theory (DFT) is the most popular of the quantum mechanical calculation approaches for probe into structures and reactivity of chemical molecules. In this study, DFT at the B3LYP/6-31G*basis set level is used to investigate and compare the molecular structure, chemical reactivity, stability, electronic and vibrational spectroscopic properties of stearic acid and palmitic acid.

\section{Results and discussion}

\subsection{Effects of HOMO-LUMO energy gap}

The study of energies of pairs of frontier orbitals, namely HOMO and LUMO of molecules provide reliable and quantitative data for straightforward prediction and comparative study of chemical and thermodynamic stabilities of molecules. It has been reported earlier that HOMO-LUMO energy gap $(\Delta \mathrm{E})$ is an important stability index [2]. A large energy gap implies higher stability and lower chemical reactivity and vice versa. From the calculations made using DFT at the B3LYP/6-31G* basis set level, while $\mathrm{E}_{\text {номо }}$ of stearic acid $(-7.47 \mathrm{eV})$ is greater than that of palmitic acid $(-7.46 \mathrm{eV})$ by $0.01 \mathrm{eV}$, the $\mathrm{E}_{\mathrm{LUMO}}$ of stearic acid $(0.29 \mathrm{eV})$ is less than that of palmitic acid $(0.30 \mathrm{eV})$ by the same amount. This suggests than stearic acid and palmitic acid are of same reactivity and stability. This can be further seen in their equal amount of $\Delta \mathrm{E}(7.76)$ value. 


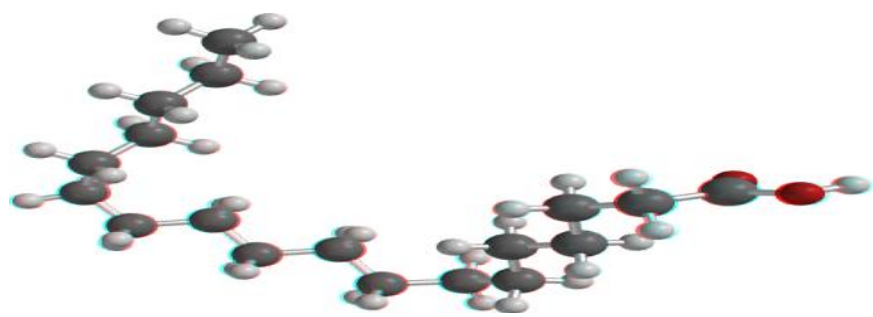

Figure 1 (a): Optimized stearic acid structure using DFT at the B3LYP/6-31G*basis set level.

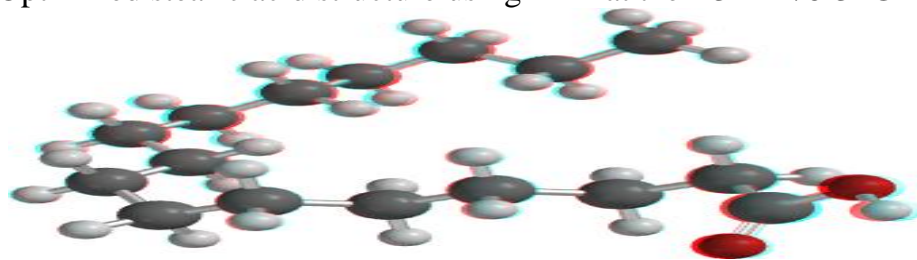

Figure 1(b): Optimized palmitic acid structure using DFT at the B3LYP/6-31G*basis set level.

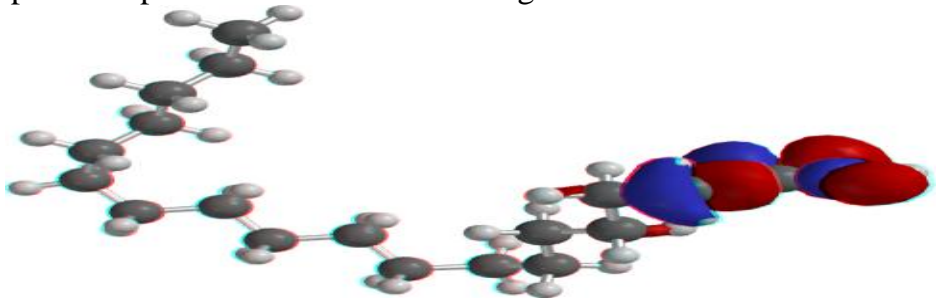

Figure 2 (a): The highest occupied molecular orbital (HOMO) density of stearic acid using DFT at the B3LYP/6-31G*basis set level.

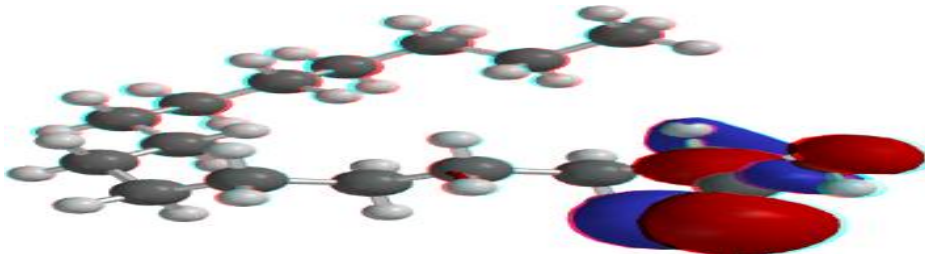

Figure 2 (b): The highest occupied molecular orbital (HOMO) density of palmitic acid using DFT at the

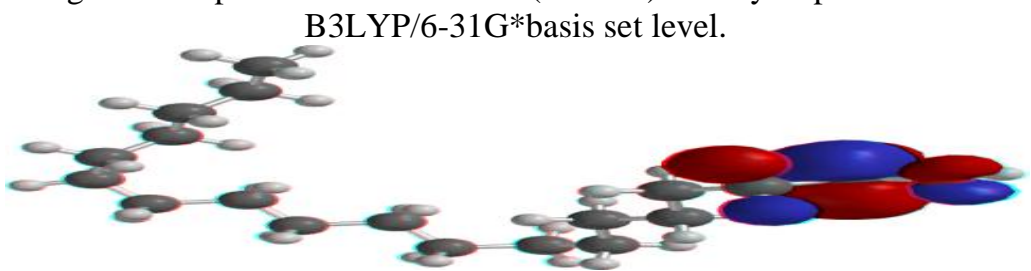

Figure 3 (a): The Lowest unoccupied molecular orbital (LUMO) density of stearic acid using DFT at the B3LYP/6-31G*basis set level.

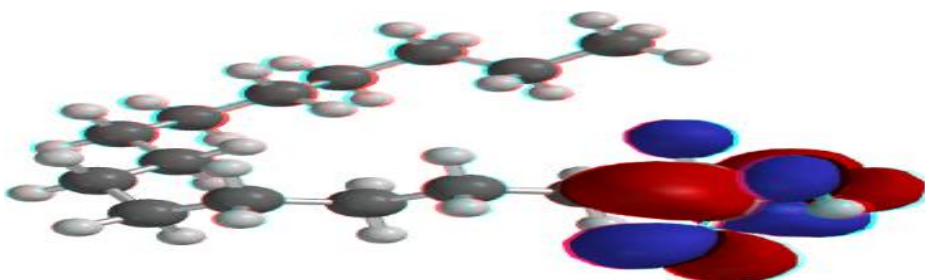

Figure 3(b): The Lowest unoccupied molecular orbital (LUMO) density of PALMITIC ACID using DFT at the B3LYP/6-31G*basis set level.

\subsection{Total Energy}

The total energy calculated by quantum mechanical method is also a beneficial parameter. The total energy determines the occurrence or non-occurrence of chemical reactions and stereospecific paths in intra- and intermolecular processes [3]. The total energy of a system is composed of the internal, potential, and kinetic energy. Hohenberg and Kohn [4] proved that the total energy of a system including that of the many body effects of electrons (exchange and correlation) in the presence of static external potential (for example, the atomic nuclei) is a unique functional of the charge density. The minimum value of the total energy functional is 
the ground state energy of the system. The electronic charge density which yields this minimum is then the exact single particle ground state energy. From our study, the total energy (absolute values) of stearic acid is higher than that of palmitic acid.

\subsection{Global hardness and global softness}

According to the HSAB principle of pearson, [5], within the framework of density functional theory, chemical reactivity and stability of a molecule is associated with its global hardness $(\alpha)$ and global softness $(\beta)$ calculated using equation 1 and 2 . Increase in hardness increases movement of the system towards a more stable configuration-equilibrium configuration. When a molecule moves away from its equilibrium configuration, its hardness value decreases. Greater hardness therefore implies high stability and low reactivity. Global softness has an inverse relationship with hardness: soft molecules undergo changes in electron density more easily than the hard molecules and are more reactive than the hard molecules [7]. Values of global hardness and global softness calculated for stearic acid and palmitic acid are similar indicating similar reactivity.

$$
\begin{aligned}
& \alpha=\Delta E / 2 \\
& \beta=1 / \alpha
\end{aligned}
$$

\subsection{Dipole moment}

Another parameter that helps in the understanding of interaction between atoms in the same or different molecules is the dipole moment. It is a measure of the net molecular polarity, which is the magnitude of charge $(/ \mathrm{Q} /)$ at the either ends of the molecular dipole time the distance between the charges. Dipole moment increases with increase in electronegativity of atoms [8]. Chemical reactivity usually increases with increase in dipole moment. The use of dipole moment to probe chemical reactivity according to our theoretical study suggests that palmitic acid $(\mu=1.28$ Debye) is more reactive than stearic acid ( $\mu=1.26$ Debye).

\subsection{Spectroscopic investigation}

Results obtained from theoretical calculation of electronic absorption wavelength and vibrational frequencies of stearic acid and palmitic acid are shown in figures 5-8. From the above figures, it may be inferred that the spectroscopic characteristics of palmitic and stearic acid are similar considering the fact that they produce similar peaks and exhibit similar spectral positions. Thus, it may be inferred that stearic acid and palmitic acid exhibit similar responses to an approaching electromagnetic field.

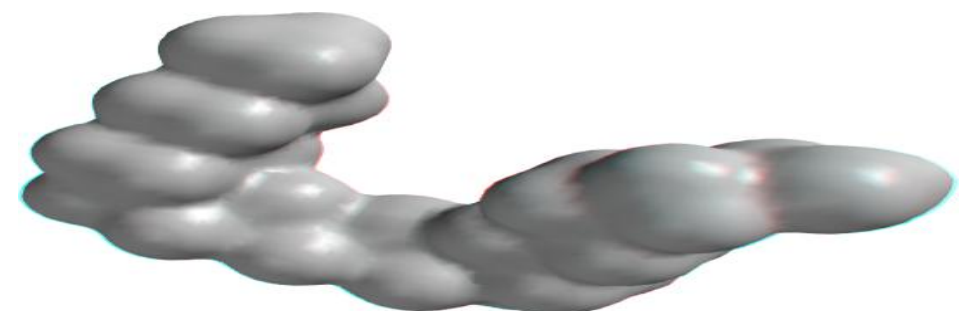

Figure 4 (a): The density of stearic acid using DFT at the B3LYP/6-31G*basis set level.

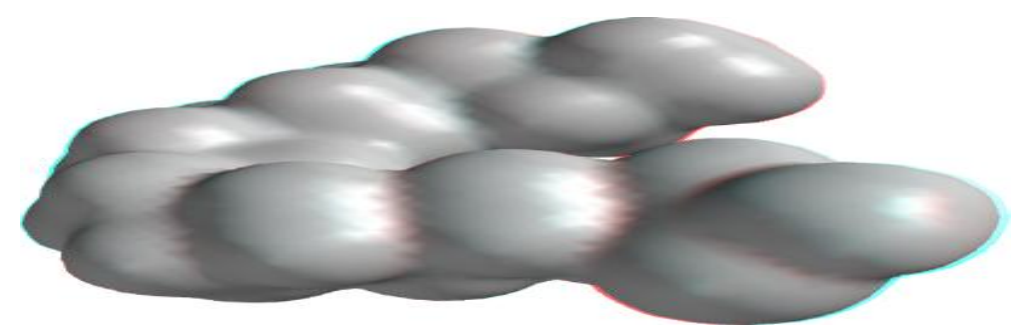

Figure 4 (b): The density of PALMITIC ACID using DFT at the B3LYP/6-31G*basis set level.

Tables 2: Some molecular properties of stearic acid and palmitic acid calculated using DFT at the B3LYP/6-

\begin{tabular}{ccc} 
& 31G* basis set level. & Palmitic acid \\
\hline Parameter & Stearic acid & -7.46 \\
\hline EHOMO (eV) & -7.47 & 0.30 \\
ELUMO (eV) & 0.29 & 7.76 \\
$\Delta \mathbf{E}(\mathbf{e V})$ & 7.76 & -21209.30056 \\
Total energy & -23348.68936 & 1.28 \\
\hline Dipole moment (Debye) & 1.26 & 3.88 \\
Global hardness & 3.88 & 0.2577 \\
\hline Global softness & 0.2577 & \\
\hline
\end{tabular}


Molecular structure, chemical reactivity, stability and vibrational spectroscopic investigation of

Table 3 (a): Mullikan charge distribution of stearic acid calculated using DFT at the B3LYP/6-31G* basis set level.

\begin{tabular}{|l|l|l|l|l|l|l|l|l|l|l|}
\hline ATOM & $\mathrm{C} 1$ & $\mathrm{O} 1$ & $\mathrm{O} 2$ & $\mathrm{H} 2$ & $\mathrm{C} 2$ & $\mathrm{H} 1$ & $\mathrm{H} 4$ & $\mathrm{C} 3$ & $\mathrm{H} 5$ \\
\hline CHARGE & +0.579 & -0.464 & -0.569 & +0.407 & -0.354 & +0.171 & +0.177 & -0.252 & +0.154 & +0.130 \\
\hline ATOM & $\mathrm{C} 4$ & $\mathrm{H} 3$ & $\mathrm{H} 7$ & $\mathrm{C} 5$ & $\mathrm{H} 9$ & $\mathrm{H} 10$ & $\mathrm{C} 6$ & $\mathrm{H} 8$ & $\mathrm{H} 11$ \\
\hline CHARGE & -0.262 & +0.122 & +0.152 & -0.254 & +0.133 & +0.132 & -0.255 & +0.125 & +0.129 & -0.260 \\
\hline ATOM & $\mathrm{H} 12$ & $\mathrm{H} 13$ & $\mathrm{C} 8$ & $\mathrm{H} 14$ & $\mathrm{H} 15$ & $\mathrm{C} 9$ & $\mathrm{H} 16$ & $\mathrm{H} 18$ & $\mathrm{C} 10$ & $\mathrm{H} 17$ \\
\hline CHARGE & +0.128 & +0.128 & -0.253 & +0.125 & +0.127 & -0.259 & +0.135 & +0.127 & -0.254 & +0.125 \\
\hline ATOM & $\mathrm{H} 19$ & $\mathrm{C} 11$ & $\mathrm{H} 20$ & $\mathrm{H} 22$ & $\mathrm{C} 12$ & $\mathrm{H} 21$ & $\mathrm{H} 23$ & $\mathrm{C} 13$ & $\mathrm{H} 25$ & $\mathrm{H} 26$ \\
\hline CHARGE & +0.126 & -0.253 & +0.133 & +0.127 & -0.255 & +0.126 & +0.126 & -0.260 & +0.128 & +0.128 \\
\hline ATOM & $\mathrm{C} 14$ & $\mathrm{H} 24$ & $\mathrm{H} 27$ & $\mathrm{C} 15$ & $\mathrm{H} 29$ & $\mathrm{H} 30$ & $\mathrm{C} 16$ & $\mathrm{H} 28$ & H31 & C17 \\
\hline CHARGE & -0.254 & +0.127 & +0.127 & -0.260 & +0.126 & +0.137 & -0.246 & +0.125 & +0.125 & -0.247 \\
\hline ATOM & $\mathrm{H} 32$ & $\mathrm{H} 34$ & $\mathrm{C} 18$ & $\mathrm{H} 33$ & $\mathrm{H} 35$ & $\mathrm{H} 36$ & & & & \\
\hline CHARGE & +0.130 & +0.130 & -0.441 & +0.140 & +0.141 & +0.141 & & & \\
\hline
\end{tabular}

Table 3 (b): Mullikan charge distribution of palmitic acid calculated using DFT at the B3LYP/6-31G* basis set level.

\begin{tabular}{|c|c|c|c|c|c|c|c|c|c|c|}
\hline ATOM & $\mathrm{C} 1$ & O1 & $\mathrm{O} 2$ & $\mathrm{H} 2$ & $\mathrm{C} 2$ & H1 & $\mathrm{H} 4$ & C3 & H5 & H6 \\
\hline CHARGE & +0.579 & -0.464 & -0.568 & +0.407 & -0.354 & +0.170 & +0.177 & -0.252 & +0.155 & +0.131 \\
\hline ATOM & $\mathrm{C} 4$ & $\mathrm{H} 3$ & $\mathrm{H} 7$ & C5 & H9 & $\mathrm{H} 10$ & C6 & H8 & H11 & C7 \\
\hline CHARGE & -0.261 & +0.122 & +0.151 & -0.261 & +0.133 & +0.133 & -0.255 & +0.126 & +0.132 & -0.260 \\
\hline ATOM & H12 & H13 & $\mathrm{C} 8$ & $\mathrm{H} 14$ & H15 & C9 & H16 & H18 & C10 & H17 \\
\hline CHARGE & +0.129 & +0.128 & -0.255 & +0.126 & +0.126 & -0.255 & +0.141 & +0.125 & -0.255 & +0.126 \\
\hline ATOM & H19 & $\mathrm{C} 11$ & $\mathrm{H} 21$ & $\mathrm{H} 22$ & C12 & $\mathrm{H} 20$ & $\mathrm{H} 24$ & C13 & $\mathrm{H} 25$ & H26 \\
\hline CHARGE & +0.127 & -0.254 & +0.126 & +0.126 & -0.256 & +0.124 & +0.137 & -0.255 & +0.127 & +0.126 \\
\hline ATOM & C14 & $\mathrm{H} 23$ & $\mathrm{H} 27$ & C15 & $\mathrm{H} 28$ & $\mathrm{H} 30$ & C16 & $\mathrm{H} 29$ & H31 & H32 \\
\hline CHARGE & -0.247 & +0.125 & +0.126 & -0.247 & +0.133 & +0.129 & -0.441 & +0.141 & +0.142 & +0.139 \\
\hline
\end{tabular}

Table 4 (a): Bond order of stearic acid calculated using DFT at the B3LYP/6-31G* basis set level.

\begin{tabular}{|c|c|c|c|c|c|c|c|c|c|c|}
\hline $\begin{array}{l}\text { BOND } \\
\text { ORDER }\end{array}$ & $\mathrm{C} 1 \mathrm{O} 1$ & $\mathrm{C} 1 \mathrm{O} 2$ & $\mathrm{C} 1 \mathrm{C} 2$ & $\mathrm{O} 1 \mathrm{O} 2$ & $\mathrm{O} 1 \mathrm{H} 2$ & $\mathrm{O} 2 \mathrm{H} 2$ & $\mathrm{C} 2 \mathrm{H} 1$ & $\mathrm{C} 2 \mathrm{H} 4$ & $\mathrm{C} 2 \mathrm{C} 3$ & $\mathrm{C} 3 \mathrm{H} 5$ \\
\hline MULLIKAN & 1.866 & 1.069 & 0.968 & 0.065 & 0.037 & 0.760 & 0.921 & 0.920 & 0.993 & 0.931 \\
\hline $\begin{array}{l}\text { BOND } \\
\text { ORDER }\end{array}$ & C3H6 & $\mathrm{C} 3 \mathrm{C} 4$ & $\mathrm{C} 4 \mathrm{H} 3$ & $\mathrm{C} 4 \mathrm{H} 7$ & C4C5 & $\mathrm{C} 5 \mathrm{H} 9$ & C5H10 & C5C6 & C6H8 & C6H11 \\
\hline MULLIKAN & 0.936 & 1.010 & 0.938 & 0.929 & 1.007 & 0.929 & 0.932 & 1.011 & 0.938 & 0.939 \\
\hline $\begin{array}{l}\text { BOND } \\
\text { ORDER }\end{array}$ & C6C7 & C7H12 & C7H13 & C7C8 & C8H14 & C8H15 & C8C9 & C9H16 & C9H18 & $\mathrm{C} 9 \mathrm{C} 10$ \\
\hline MULLIKAN & 1.014 & 0.942 & 0.938 & 0.995 & 0.939 & 0.942 & 1.012 & 0.930 & 0.938 & 1.005 \\
\hline $\begin{array}{l}\text { BOND } \\
\text { ORDER }\end{array}$ & $\begin{array}{l}\text { C10H1 } \\
7\end{array}$ & $\begin{array}{l}\text { C10H1 } \\
9\end{array}$ & C10C11 & $\mathrm{C} 11 \mathrm{H} 20$ & $\mathrm{C} 11 \mathrm{H} 22$ & C11C12 & $\mathrm{C} 12 \mathrm{H} 21$ & $\begin{array}{l}\mathrm{C} 12 \mathrm{H} 2 \\
3\end{array}$ & C12C13 & $\begin{array}{l}\mathrm{C} 13 \mathrm{H} 2 \\
5\end{array}$ \\
\hline MULLIKAN & 0.939 & 0.938 & 1.003 & 0.933 & 0.938 & 1.011 & 0.938 & 0.939 & 1.014 & 0.943 \\
\hline $\begin{array}{l}\text { BOND } \\
\text { ORDER }\end{array}$ & $\begin{array}{l}\text { C13H2 } \\
6\end{array}$ & C13C14 & C14H24 & C14H27 & C14C15 & $\mathrm{C} 15 \mathrm{H} 29$ & $\mathrm{C} 15 \mathrm{H} 30$ & $\begin{array}{l}\text { C15C1 } \\
6\end{array}$ & $\mathrm{C} 16 \mathrm{H} 28$ & $\begin{array}{l}\text { C16H3 } \\
1\end{array}$ \\
\hline MULLIKAN & 0.939 & 0.989 & 0.939 & 0.943 & 1.011 & 0.938 & 0.932 & 1.007 & 0.939 & 0.933 \\
\hline $\begin{array}{l}\text { BOND } \\
\text { ORDER }\end{array}$ & $\begin{array}{l}\text { C16C1 } \\
7\end{array}$ & $\begin{array}{l}\text { C17H3 } \\
2\end{array}$ & C17H34 & C17C18 & C18H33 & $\mathrm{C} 18 \mathrm{H} 35$ & $\mathrm{C} 18 \mathrm{H} 36$ & & & \\
\hline MULLIKAN & 1.011 & 0.942 & 0.943 & 1.016 & 0.953 & 0.952 & 0.952 & & & \\
\hline
\end{tabular}

Table 4 (b): Bond order of palmitic acid calculated using DFT at the B3LYP/6-31G* basis set level.

\begin{tabular}{|l|l|l|l|l|l|l|l|l|l|l|}
\hline $\begin{array}{l}\text { BOND } \\
\text { ORDER }\end{array}$ & $\mathrm{C} 1 \mathrm{O} 1$ & $\mathrm{C} 1 \mathrm{O} 2$ & $\mathrm{C} 1 \mathrm{C} 2$ & $\mathrm{O} 1 \mathrm{O} 2$ & $\mathrm{O} 1 \mathrm{H} 2$ & $\mathrm{O} 2 \mathrm{H} 2$ & $\mathrm{C} 2 \mathrm{H} 1$ & $\mathrm{C} 2 \mathrm{H} 4$ & $\mathrm{C} 2 \mathrm{C} 3$ & $\mathrm{C} 3 \mathrm{H} 5$ \\
\hline MULLIKAN & 1.865 & 1.070 & 0.967 & 0.065 & 0.037 & 0.760 & 0.921 & 0.920 & 0.993 & 0.931 \\
\hline $\begin{array}{l}\text { BOND } \\
\text { ORDER }\end{array}$ & $\mathrm{C} 3 \mathrm{H} 6$ & $\mathrm{C} 3 \mathrm{C} 4$ & $\mathrm{C} 4 \mathrm{H} 3$ & $\mathrm{C} 4 \mathrm{H} 7$ & $\mathrm{C} 4 \mathrm{C} 5$ & $\mathrm{C} 5 \mathrm{H} 9$ & $\mathrm{C} 5 \mathrm{H} 10$ & $\mathrm{C} 5 \mathrm{C} 6$ & $\mathrm{C} 6 \mathrm{H} 8$ & $\mathrm{C} 6 \mathrm{H} 11$ \\
\hline MULLIKAN & 0.936 & 1.010 & 0.938 & 0.930 & 1.009 & 0.938 & 0.931 & 1.012 & 0.939 & 0.942 \\
\hline $\begin{array}{l}\text { BOND } \\
\text { ORDER }\end{array}$ & $\mathrm{C} 6 \mathrm{C} 7$ & $\mathrm{C} 7 \mathrm{H} 12$ & $\mathrm{C} 7 \mathrm{H} 13$ & $\mathrm{C} 7 \mathrm{C} 8$ & $\mathrm{C} 8 \mathrm{H} 14$ & $\mathrm{C} 8 \mathrm{H} 15$ & $\mathrm{C} 8 \mathrm{C} 9$ & $\mathrm{C} 9 \mathrm{H} 16$ & $\mathrm{C} 9 \mathrm{H} 18$ & $\mathrm{C} 9 \mathrm{C} 10$ \\
\hline MULLIKAN & 0.990 & 0.943 & 0.938 & 1.013 & 0.938 & 0.939 & 1.012 & 0.927 & 0.938 & 1.006 \\
\hline $\begin{array}{l}\text { BOND } \\
\text { ORDER }\end{array}$ & $\mathrm{C} 10 \mathrm{H} 17$ & $\mathrm{C} 10 \mathrm{H} 19$ & $\mathrm{C} 10 \mathrm{C} 11$ & $\mathrm{C} 11 \mathrm{H} 21$ & $\mathrm{C} 11 \mathrm{H} 22$ & $\mathrm{C} 11 \mathrm{C} 12$ & $\mathrm{C} 12 \mathrm{H} 20$ & $\mathrm{C} 12 \mathrm{H} 24$ & $\mathrm{C} 12 \mathrm{C} 13$ & $\mathrm{C} 13 \mathrm{H} 25$ \\
\hline MULLIKAN & 0.938 & 0.939 & 1.003 & 0.939 & 0.938 & 1.009 & 0.939 & 0.930 & 1.009 & 0.940 \\
\hline $\begin{array}{l}\text { BOND } \\
\text { ORDER }\end{array}$ & $\mathrm{C} 13 \mathrm{H} 26$ & $\mathrm{C} 13 \mathrm{C} 14$ & $\mathrm{C} 14 \mathrm{H} 23$ & $\mathrm{C} 14 \mathrm{H} 27$ & $\mathrm{C} 14 \mathrm{C} 15$ & $\mathrm{C} 15 \mathrm{H} 28$ & $\mathrm{C} 15 \mathrm{H} 30$ & $\mathrm{C} 15 \mathrm{C} 16$ & $\mathrm{C} 15 \mathrm{H} 29$ & $\mathrm{C} 16 \mathrm{H} 31$ \\
\hline MULLIKAN & 0.938 & 1.004 & 0.938 & 0.940 & 1.015 & 0.939 & 0.943 & 1.015 & 0.952 & 0.952 \\
\hline
\end{tabular}




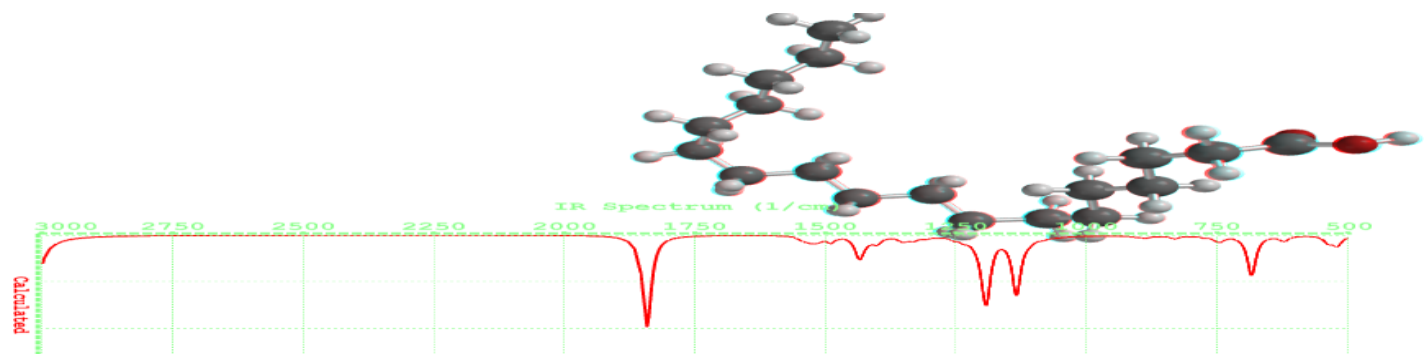

Figure 5 (a): Infra-red spectra of stearic acid using DFT at the B3LYP/6-31G* basis set level.

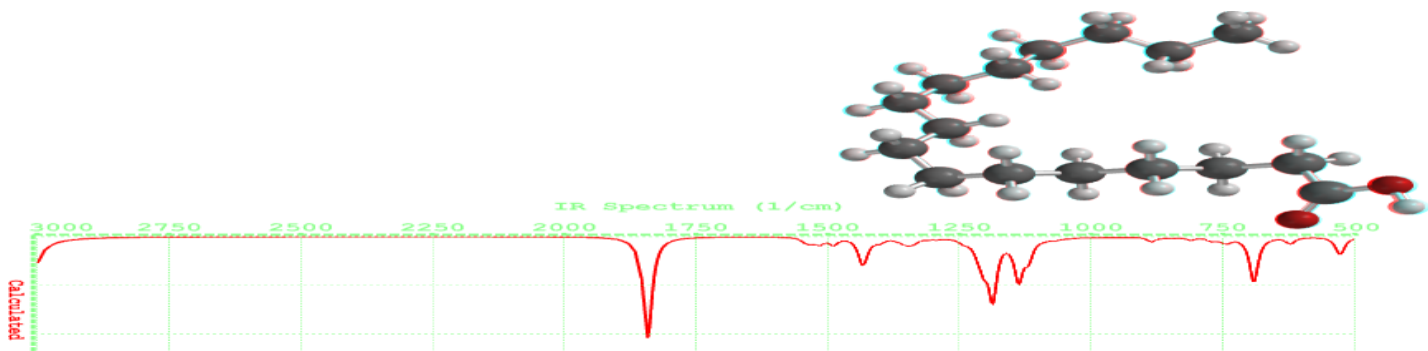

Figure 5 (b): Infra-red spectra of palmitic acid using DFT at the B3LYP/6-31G* basis set level.

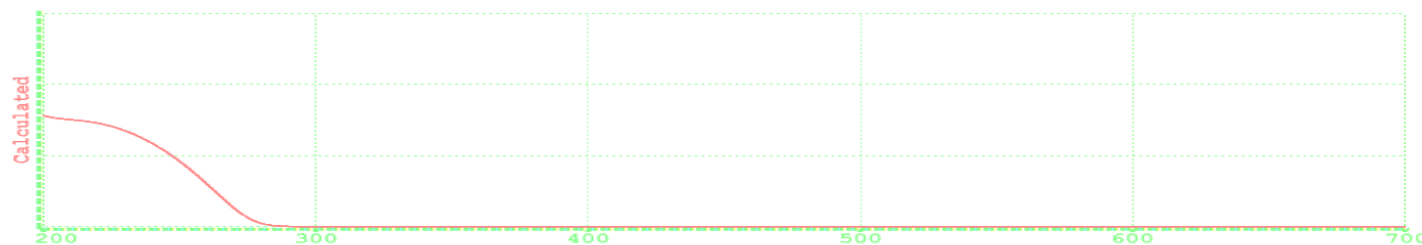

Figure 6 (a): Ultra-violet spectra of stearic acid using DFT at the B3LYP/6-31G* basis set level.

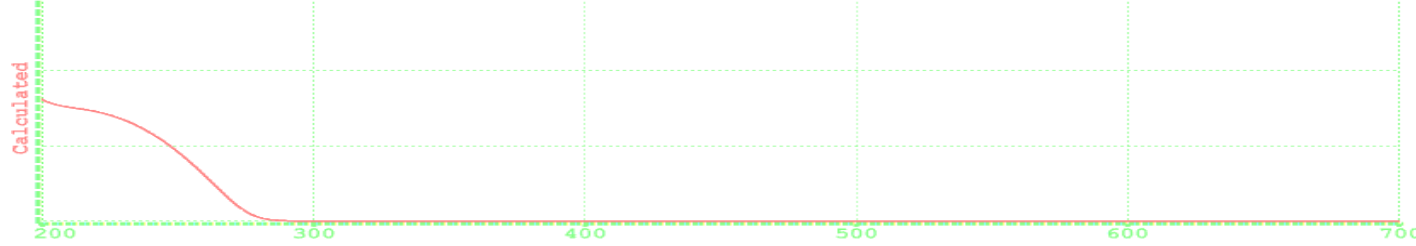

Figure 6 (b): Ultra-violet spectra of palmitic acid using DFT at the B3LYP/6-31G* basis set level

\section{Conclusions}

On the basis of this study, it has been concluded that stearic acid and palmitic acid have similar spectral positions, similar global hardness and global softness hence similar chemical reactivity and stability. Energy gap of frontier orbitals of both fatty acids are also similar. However, slight differences in dipole moment suggests possibility of higher reactivity of palmitic acid than stearic acid.

\section{References}

[1]. Gunstone, F. D., John L. Harwood, and Albert J. Dijkstra. Boca Raton: CRC Press, 2007. ISBN 0849396883 | ISBN 9780849396885

[2]. Faust, W. L. Science. 245 (1989) 37.

[3]. Fukui, K. Science.218 (1982) 747.

[4]. Pearson, R. G. J. Chem. Phys. 52(1970) 2167, 53 (1970) 2986.

[5]. Pearson, R. G. J. Am. Chem. Soc. 91(1969) 1252, 4947.

[6]. Pearson, R. G., J. Am. Chem. Soc. 85 (1963)353; Science. 151 (1966) 172

[7]. I. B. Obot and A. S. Johnson. Comput. Chem. 43 (2012) 6658.

[8]. N. O. Obi-Egbedi, I. B. Obot, M. I. El-khaiary. J. Mol. Struct. 1002 (2011) 86 